\title{
An epidemiological study of congenital reduction deformities of the limbs
}

\author{
E. S. O. SMITH', CHARLOTTE S. DAFOE2, JAMES R. MILLER 3, AND \\ PHILIP BANISTER 4
}

From the Division of Epidemiology, Alberta Department of Health and Social Development ', and the Registry for Handicapped Children and Adults, Alberta Department of Health and Social Development, Edmonton', the Department of Medical Genetics, University of British Columbia, Vancouver ${ }^{3}$, and the Bureau of Surveillance Services, Department of National Health and Welfare, Ottawa

SUMMARY A retrospective study that was undertaken to determine why more infants had been born with congenital reduction deformities of the limbs is reported. The increase was detected by the Congenital Anomaly Surveillance System in 1969. Ninety-three infants born in Alberta and British Columbia in 1969-71 with congenital reduction deformities were matched with 93 normal infants and 93 infants with congenital malformations of a different type. The mothers of all infants were interviewed to obtain information on factors thought relevant to the establishment of a causal relationship. Although there were some significant differences between cases and normal and/or abnormal controls, this number of differences might have been expected by chance. No single causal relationship was established.

The protection of the public from the introduction of a new teratogen into the environment is one of the roles of a government health agency. This may be achieved partly by testing products for safety, using laboratory animals, before they are released for human consumption, and partly by looking for unexpected teratogenic effects in the population after the products have been in general use. This will involve the detection of a clustering of congenital malformations in time and space, and the identification of the cause of the cluster.

In Canada, provincial and federal governments have been trying to obtain both sorts of evidence. Clusterings of congenital malformations are detected by a surveillance system for congenital anomalies, co-ordinated at federal level (Banister, 1971). However, even if there is adequate reporting of cases and a satisfactory baseline to permit detection of clustering, the problems of identifying a causal agent or circumstance remain significant.

The value of the methods used in a retrospective search for the cause of a sudden increase in the incidence of congenital reduction deformities of the limbs in the province of Alberta is illustrated. A limb reduction deformity is defined as an absence of bone or cartilage, and/or absence of digit, hand, foot, forearm, leg, arm, thigh. This increase was first detected by the Congenital Anomaly Surveillance System in June 1969. A preliminary report (Banister, 1970) did not identify a causal agent, but suggested the need for a more detailed investigation.

Further papers in the scientific literature (Janerich et al., 1974; Jaffe et al., 1975; Canadian Medical Association Journal, 1975) on congenital reduction deformities of the limbs, published after this study, suggest a continuing interest in the subject.

\section{Description of study}

The cases included in this study were born between 1 January 1969 and 31 December 1971 and taken from vital statistics-that is, doctor's notice of live birth or stillbirth with a description of any congenital anomalies, and from death certificates which list causes of death, stillbirth, and associated conditions. All cases known to the surveillance system as having limb anomalies were reviewed and if the description was vague - for example, phocomelia - a follow-up through the provincial health departments and physicians was attempted. Starting in 1970 the hospital discharge notification form containing the discharge diagnoses was added to the existing documents being screened for congenital anomalies. No special attempts were made to encourage 
reporting. Table 1 shows the number of infants thus reported born with congenital reduction deformities for the years 1966-75 inclusive. Since 1970 the proportion affected has tended to be higher, perhaps because of improved ascertainment.

Table 1 Congenital reduction deformities of limbs reported in Alberta and British Columbia among infants born during 1966-75

\begin{tabular}{|c|c|c|c|c|}
\hline \multirow[b]{2}{*}{ Year } & \multicolumn{2}{|c|}{ Alberta } & \multicolumn{2}{|c|}{ British Columbia } \\
\hline & Cases & $\begin{array}{l}\text { Frequency } \\
\text { per } 100000 \\
\text { live births }\end{array}$ & Cases & $\begin{array}{l}\text { Frequency } \\
\text { per } 100000 \\
\text { live births }\end{array}$ \\
\hline $\begin{array}{l}1966 \\
1967 \\
1968 \\
1969 \\
1970 \\
1971 \\
1972 \\
1973 \\
1974 \\
1975^{*}\end{array}$ & $\begin{array}{r}10 \\
7 \\
17 \\
20 \\
26 \\
18 \\
14 \\
18 \\
20 \\
16\end{array}$ & $\begin{array}{l}32 \cdot 7 \\
22 \cdot 8 \\
56 \cdot 4 \\
64 \cdot 8 \\
81 \cdot 3 \\
58 \cdot 9 \\
47 \cdot 8 \\
61 \cdot 5 \\
67 \cdot 5 \\
49 \cdot 6\end{array}$ & $\begin{array}{l}13 \\
15 \\
15 \\
16 \\
32 \\
19 \\
21 \\
28 \\
20 \\
20\end{array}$ & $\begin{array}{l}40 \cdot 0 \\
45 \cdot 6 \\
44 \cdot 5 \\
45 \cdot 2 \\
86 \cdot 8 \\
54 \cdot 5 \\
60 \cdot 8 \\
81 \cdot 5 \\
56 \cdot 6 \\
56 \cdot 4\end{array}$ \\
\hline
\end{tabular}

*Reported to 31 December 1976

This report is based on 93 cases, comprising 54 out of 64 reported cases during a three-year period (1969-71) in Alberta and 39 out of 51 reported cases during a two-year period (1970-71) in British Columbia which was included in the study in 1970 because it also appeared to be affected by the trend. Cases were excluded if the mothers were not resident in either province during the early stages of pregnancy and when the reduction deformities were a manifestation of a syndrome of known genetic aetiology. These exclusions may not have been complete; some families had left the provinces by the time of follow-up and were unavailable.

For each index case two controls were selected from a doctor's notice of live birth or stillbirth (on which, in both Alberta and British Columbia, congenital malformations are reportable): one normal infant, called the normal control, and one infant with a congenital anomaly other than a limb reduction deformity, called the anomalous control. Controls were matched as closely as possible for date of birth ( \pm 2 weeks), district of residence, period of gestation ( \pm 2 weeks), age of mother ( \pm 3 years), parity of mother and, in the event of choice, sex of child.

A self-coding questionnaire was designed and tested at the end of 1969 to provide the following information:

1. Details of identification;

2. Characteristics of child, including assessment of reduction deformity and presence or absence of other congenital anomalies;
3. Presence or absence of limb reduction deformities or other congenital anomalies in $\frac{3}{8}$ siblings and half-siblings of each sex;

4. Characteristics of father and mother, their $\overrightarrow{\vec{A}}$ siblings and their parents, including a record of consanguineous marriages;

5. Preconception environmental influences, in- $\frac{\bar{c}}{\bar{D}}$ cluding radiation and drugs, in father and in $\vec{\varnothing}$ mother;

6. History of previous pregnancies;

7. Method of contraception if practised;

8. Environmental influences during early preg- $\vec{\omega}$ nancy (first trimester) and late pregnancy? (second and third trimesters), including $\frac{\Phi}{\circ}$ radiation, drugs, other chemical influences, $\vec{\omega}$ dietary factors, infection, and trauma;

9. Complications of pregnancy.

The questionnaire embodied an original method 0 for describing the anatomical profile of a reduction deformity. Each limb was separately assessed, and $\bar{z}$ each of its five segments (humerus or femur, radiusulna or tibia fibula, carpals or tarsals, metacarpals $\stackrel{\rho}{\supset}$ or metatarsals, phalanges) was quantitatively coded $\overrightarrow{0}$ as normal, reduced, or absent.

The information was obtained for cases an controls by an interview with the mother. The $\bar{s}$ were conducted in Alberta by one of the co-authors (CSD), and in British Columbia by two public health nurses. There were very few refusals. In the event of an interview refusal or a family move involving $\cong$ a control case, another control was selected. With $\overrightarrow{\overrightarrow{0}}$ a view to corroborating and supplementing the 3 information gathered from the mother, a short questionnaire was sent to her doctor. However, the response to these questionnaires was poor.

\section{Results}

The anomalies observed among index cases ranged from minor digital amputations to missing limbs.

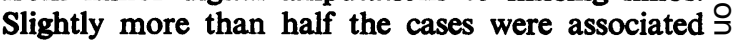
with other kinds of congenital malformations, $\rightarrow$ among which musculoskeletal, cardiovascular, and genitourinary defects were the most frequent. $N$

Results that did not appear to contribute to a solution of the cause were seasonal distribution of

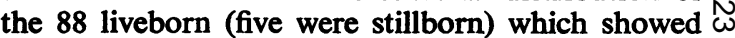
no significant departure from vital statistics data based on the accumulated experience of Alberta $\varphi$ and British Columbia for the years of the study.

The mean ages of mother (25.8 years) and father $\stackrel{?}{-}$ (29.2 years) were comparable with those obtained $T$ from vital statistics data, and the distribution of maternal and paternal ages showed no significant $\stackrel{\Phi}{\Phi}$ 
deviation from the expected distributions. An observation of unknown biological significance was that among the 86 liveborn index cases for which information was available, the mean gestation period (38.6 \pm 2.93 weeks) differed significantly $(P<0.01)$ from that derived from vital statistics $(39 \cdot 4 \pm 2 \cdot 11$ weeks).

Most (136) of the questionnaire items could be answered by yes or no. These 136 questions were compared using the normal approximation for the difference in proportions. This makes it likely that several answers were designated as being statistically significant when in fact they would not be found significant if an exact probability test of proportions or if a contingency table approach had been used. Accordingly, Yates's correction was applied to the significant items. Table 2 lists the items originally designated as significant and the $\chi^{2}$ values with Yates's correction.

\section{Discussion}

Several observations may be made about Table 2. The most important is that for the 136 yes-no items in the questionnaire, the number of significant responses in Table 2 is no greater than might have been expected by chance. The study thus failed to demonstrate any single cause for what was interpreted as an increased incidence of congenital reduction deformities of the limbs. In particular, no positive association between the use of oral contraceptives and congenital reduction deformity of the limbs was noted, although such a link was reported by Janerich et al. (1974).

The observation that foam and jelly vaginal contraceptive agents had been used by 11 case mothers led to a review of these preparations. Some contained substances known to be teratogenic in animals, thus pointing out the possible importance of this route of exposure to teratogens.

As well as being reassuring, we believe the study shows the feasibility of carrying out such a retrospective inquiry reasonably promptly after a time-space clustering of congenital malformations. British Columbia and Alberta are large with scattered populations and with temperatures in winter as low as $-45^{\circ} \mathrm{C}$. The degree of success of follow-up is a tribute to the interviewers. It is essential that for proper surveillance mechanisms for adequate follow-up of suspicious episodes are available and are used; data accumulation per se is not enough.

This study was made possible by National Health Grant No. 608-7-144. We thank Dr C. L. Pearson, Mrs Lynn Heard, and Mr Brault Kelpin.

Acknowledgements are extended to Miss A. E. Scott, Miss B Tokarow, Mrs Maureen Warden, Mrs Fearon Blair, Mrs Y. Kawamoto and to $\mathbf{M r}$ D. Morrison.

Reprints from Philip Banister, Health Protection Branch, Department of National Health and Welfare, Tunney's Pasture, Ottawa, Ontario K1A0L2.

\section{References}

Banister, P. (1970). Congenital malformations: preliminary report of an investigation of reduction deformities of the limbs triggered by a pilot surveillance system. Canadian Medical Association Journal, 103, 466-472.

Banister, P. (1971). Evaluation of Vital Record Usage for Congenital Anomaly Surveillance. Monitoring, Birth Defects and Environment, p. 119. Edited by E. B. Hook, D. T. Janerich, and I. H. Porter. Academic Press: New York and London.

Canadian Medical Association Journal (1975). Editorial. Oral contraceptives and congenital limb defects. 112, 551.

Jaffe, P., Liberman, M. M., McFadyen, I., and Valman, H. B. (1975). Incidence of congenital limb-reduction deformities. Lancet, 1, 526-527.

Janerich, D. T., Piper, J. M., and Glebatis, D. M. (1974). Oral contraceptives and congenital limb-reduction defects. New England Journal of Medicine, 291, 697-700.

Table 2 Questionnaire (to which Yates's corrected statistical test was applied)

\begin{tabular}{|c|c|c|c|c|c|c|}
\hline \multirow[b]{2}{*}{ Questions } & \multicolumn{3}{|c|}{ Frequency of affirmative responses } & \multicolumn{3}{|c|}{ Index cases tested against controls } \\
\hline & $\begin{array}{l}\text { Index } \\
\text { cases } \\
(N=93)\end{array}$ & $\begin{array}{l}\text { Normal } \\
\text { controls } \\
(N=93)\end{array}$ & $\begin{array}{l}\text { Anomalous } \\
\text { controls } \\
(N=93)\end{array}$ & $\begin{array}{l}\text { Normal } \\
\chi_{c}^{2}\end{array}$ & $\begin{array}{l}\text { Anomalous } \\
\chi_{\mathrm{c}}^{2}\end{array}$ & $\begin{array}{l}\text { Both } \\
\chi_{\mathrm{c}}^{2}\end{array}$ \\
\hline $\begin{array}{l}\text { Consanguinity between mother's parents } \\
\text { Preconception use of cannabis by mother } \\
\text { Oral contraceptives } \\
\text { Contraceptive foam or jelly } \\
\text { Tranquilisers (1st trimester) } \\
\text { Tranquilisers (2nd and 3rd trimesters) } \\
\text { Antihistamines (1st trimester) } \\
\text { Antihistamines (2nd and 3rd trimesters) } \\
\text { Threatened abortion } \\
\text { Hydramnios }\end{array}$ & $\begin{array}{r}4 \\
1 \\
35 \\
11 \\
14 \\
12 \\
8 \\
8 \\
24 \\
12\end{array}$ & $\begin{array}{r}0 \\
5 \\
50 \\
4 \\
5 \\
5 \\
2 \\
2 \\
10 \\
3\end{array}$ & $\begin{array}{r}3 \\
3 \\
41 \\
4 \\
6 \\
6 \\
4 \\
5 \\
13 \\
9\end{array}$ & $\begin{array}{l}2 \cdot 300 \\
1 \cdot 550 \\
4 \cdot 247^{*} \\
2 \cdot 611 \\
3 \cdot 752 \dagger \\
2 \cdot 331 \\
2 \cdot 642 \\
2 \cdot 642 \\
6 \cdot 082^{*} \\
4 \cdot 641^{*}\end{array}$ & $\begin{array}{l}0 \cdot 000 \\
0 \cdot 256 \\
0 \cdot 556 \\
2 \cdot 611 \\
2 \cdot 745 \dagger \\
1 \cdot 538 \\
0 \cdot 802 \\
0 \cdot 331 \\
3 \cdot 374 \dagger \\
0 \cdot 215\end{array}$ & $\begin{array}{l}0 \cdot 898 \\
1 \cdot 163 \\
2 \cdot 752 \dagger \\
4 \cdot 412 \\
5 \cdot 278 \\
3 \cdot 133 \dagger \\
2 \cdot 717 \dagger \\
1.982 \\
7 \cdot 065 \ddagger \\
2 \cdot 513\end{array}$ \\
\hline
\end{tabular}

Significant levels: $\dagger 10 \% * 5 \%, \ddagger 1 \%$. 